\title{
Lighthearted: Pneumopericardium after mitral valve repair
}

\author{
Samuel Heuts, MD, ${ }^{\mathrm{a}, \mathrm{b}}$ Firas al Khoury, MD, ${ }^{\mathrm{a}}$ and Peyman Sardari Nia, MD, PhD ${ }^{\mathrm{a}, \mathrm{b}}$
}

\footnotetext{
From the ${ }^{\mathrm{a}}$ Department of Cardiothoracic Surgery, Maastricht University Medical Center, Maastricht, The Netherlands; and ${ }^{\mathrm{b}}$ Cardiovascular Research Institute Maastricht (CARIM), Maastricht University, Maastricht, The Netherlands.

Disclosures: Authors have nothing to disclose with regard to commercial support.

Received for publication July 6, 2018; revisions received Aug 15, 2018; accepted for publication Aug 28, 2018; available ahead of print Oct 23, 2018.

Address for reprints: Samuel Heuts, MD, Department of Cardiothoracic Surgery, Maastricht University Medical Center +, P. Debyelaan 25, 6229HX, Maastricht, The Netherlands (E-mail: sam.heuts@mumc.nl).

J Thorac Cardiovasc Surg 2019;158:e169-70

$0022-5223 / \$ 36.00$

Copyright (C) 2018 by The American Association for Thoracic Surgery

https://doi.org/10.1016/j.jtcvs.2018.08.105
}

Video clip is available online.

Although pneumopericardium is a known cause of cardiac tamponade in patients with trauma or in newborn infants, ${ }^{1}$ we describe a postoperative pericardium after mitral valve repair.

A 60-year-old man had development of progressive respiratory insufficiency and hypotension 5 days after mitral valve repair through a median sternotomy for infective mitral valve endocarditis. Intraoperatively, the sternum was approximated with 3 single wires in the

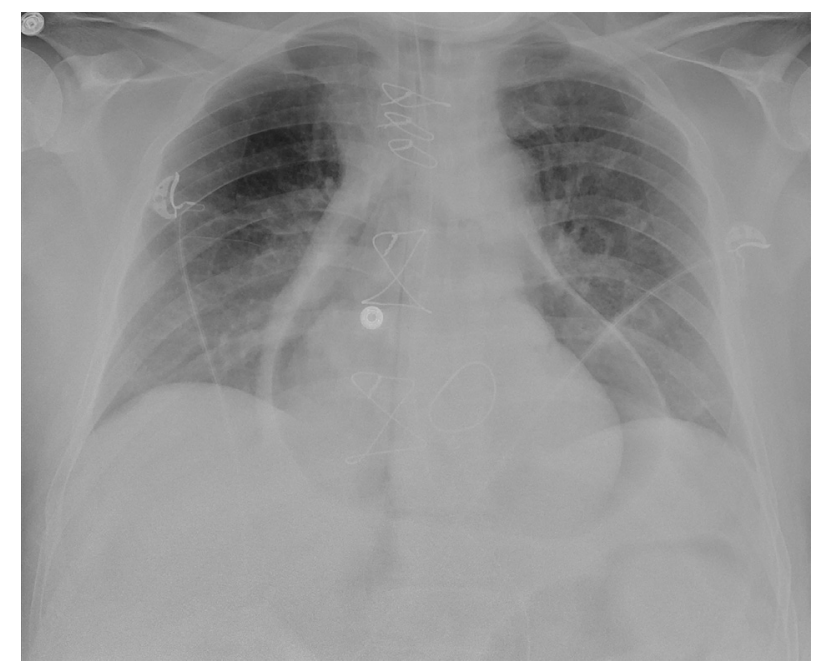

FIGURE 1. Anteroposterior chest radiograph showing the presence of air in the pericardium. dressings.

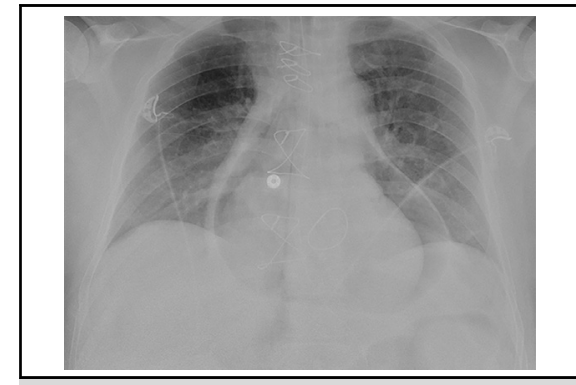

Lighthearted: Evident pneumopericardium on conventional anteroposterior chest radiograph.

Central Message
Postoperative pneumopericardium is an un-
common life-threatening complication that
can easily be detected with conventional imag-
ing techniques and treated by needle aspiration.

See Commentary page e171.

manubrium and 2 figure-of-eight wires in the corpus of the sternum. The wound was closed in 3 layers (fascia, subcutaneous tissue, and skin with intradermal sutures), chest tubes were removed after 48 hours, and chest tube sites were sutured and covered with occlusive

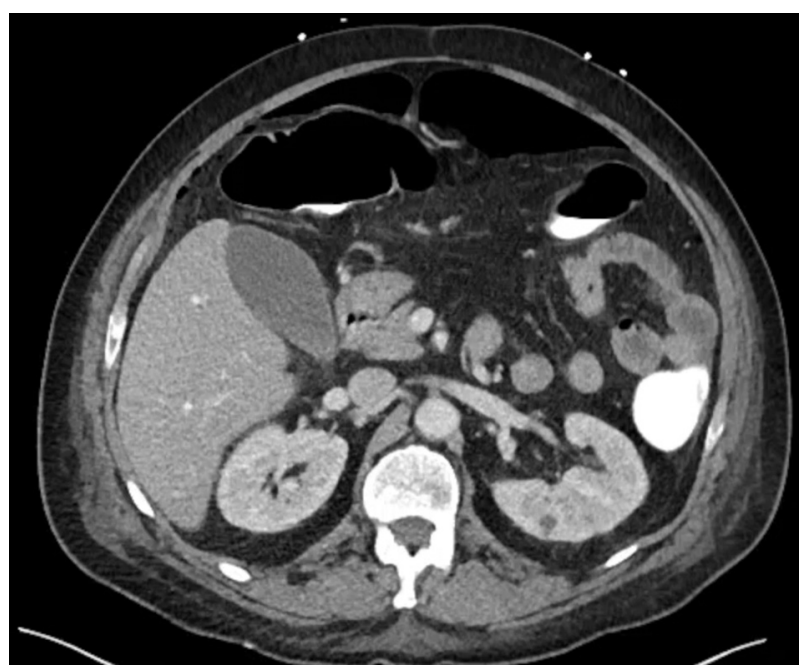

VIDEO 1. Transverse, coronal, and sagittal computed tomographic images demonstrating communication between the skin, the pericardium, and the peritoneum, with free air in the abdomen. Video available at: https://www.jtcvs.org/article/S0022-5223(18)32500-5/fulltext. 
Chest radiography on postoperative day 5 showed an evident pneumopericardium (Figure 1). Physical examination revealed a visible dynamic separation of the sternal wound edges on inspiration. The negative intrathoracic pressure during inspiration caused air to be sucked into the pericardium with each breath; this air became trapped when the sternal wound closed during exhalation, comparable to the development of a tension pneumothorax caused by a 1-way valve mechanism. Additional computed tomography revealed free air and fluid in the abdomen from an accidental opening (7 $\mathrm{mm}$ in diameter) of the peritoneal reflection at the junction between pericardium and diaphragm (Video 1). On the basis of this observation on computed tomography, we hypothesize that acute cardiac tamponade was avoided because the trapped air could escape into the abdomen.
Although several treatment options have been described previously, ${ }^{2}$ in this case the patient was treated with needle aspiration of the pneumopericardium through a subxiphoid approach. The wound was sealed with an occlusive dressing of sterile gauzes with Vaseline covering (Unilever PLC, Rotterdam, The Netherlands), fixed by air-tight Tegaderm film (Tegaderm; 3M Health Care, St Paul, Minn). The pneumoperitoneum was treated conservatively. At maximum follow-up ( 2 years), the patient remains in good clinical condition, without any sternal instability or recurrence of pneumopericardium or pneumoperitoneum.

\section{References}

1. Cummings RG, Wesly RL, Adams DH, Lowe JE. Pneumopericardium resulting in cardiac tamponade. Ann Thorac Surg. 1984;37:511-8.

2. Petteruti F, Stassano P, De Luca G, Di Tommaso L, Luciano A, Pepino P. Tension pneumopericardium and pneumothorax during spontaneous ventilation. J Thorac Cardiovasc Surg. 2007;133:829-30. 